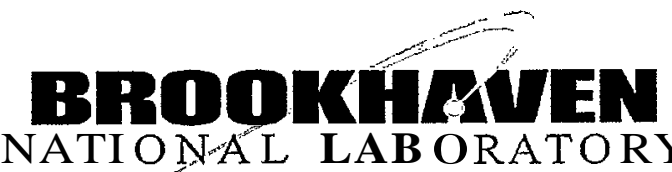

BNL-73480-2005-CP

\section{TomographicMeasurement of Longitudinal Emittance Growth Due to Stripping Foils}

\author{
C. Montag, L. Ahrens, P. Thieberger \\ Presented at the Particle Accelerator Conference(PAC'05) \\ Knoxville, Tennessee \\ May 16-20, 2005
}

\author{
Collider-Accelerator Department \\ Brookhaven National Laboratory \\ P.O. Box 5000 \\ Upton, NY 11973-5000 \\ www.bnl.gov \\ Managed by \\ Brookhaven Science Associates, LLC \\ for the United States Department of Energy under \\ Contract No. DE-AC02-98CH10886
}

This is a preprint of a paper intended for publication in a journal or proceedings. Since changes may be made before publication, this preprint is made availablewith the understandingthat itwill not be cited or reproduced without the permission of the author. 


\section{DISCLAIMER}

This report was prepared as an account of work sponsored by an agency of the United States Government. Neither the United States Government nor any agency thereof, nor any of their employees, nor any of their contractors, subcontractors, or their employees, makes any warranty, express or implied, or assumes any legal liability or responsibility for the accuracy, completeness, or any third party's use or the results of such use of any information, apparatus, product, or process disclosed, or represents that its use would not infringe privately owned rights. Reference herein to any specific commercial product, process, or service by trade name, trademark, manufacturer, or otherwise, does not necessarily constitute or imply its endorsement, recommendation, or favoring by the United States Government or any agency thereof or its contractors or subcontractors. The views and opinions of authors expressed herein do not necessarily state or reflect those of the United States Government or any agency thereof.

FOR UNCLASSIFIED, UNLIMITED STI PRODUCTS

Available electronically at:

OSTI:

http://www.os ti.gov/bridge

Available for a processing fee to U.S. Department of Energy and its contractors, in paper from:

U.S. Department of Energy

Office of Scientific and Technical Information

P.O. Box 62

Oak Ridge, TN 37831

Phone: (865) 576-8401

Facsimile: (865) 576-5728

E-mail: reports@adonis.osti.gov

National Technical Information Service (NTIS):

Available for sale to the public from:

U.S. Department of Commerce

National Technical Information Service

5285 Port Royal Road

Springfield, VA 22131

Phone: (800) 553-6847

Facsimile: (703) 605-6900

Online ordering: http://www.ntis.gov/ordering.htm

(9) Frinton an rapted gapar 


\title{
TOMOGRAPHIC MEASUREMENT OF LONGITUDINAL EMITTANCE GROWTH DUE TO STRIPPING FOILS *
}

\author{
C. Montag, L. Ahrens, P. Thieberger, Brookhaven National Laboratory, Upton, NY 11973, USA
}

\begin{abstract}
During beam acceleration in the Brookhaven accelerator complex, heavy ions are stripped of their electrons in several steps. Depending on the properties of the stripping foils, this process results in an increased energy spread and longitudinal emittancegrowth. A tomographicphase space reconstruction technique has been applied to measure the associated emittance growth for different stripping foil materials.
\end{abstract}

\section{INTRODUCTION}

The heavy ion injector chain of the Relativistic Heavy Ion Collider (RHIC) consists of a Tandem van de Graaff, the Booster Synchrotron, and the Alternating Gradient Synchrotron(AGS). Negatively charged gold ions are produced at the ion source, and stripped to a charge state of +12 during acceleration in the Tandem. From there, they are injected into the Booster via the Tandem-to-Booster (TtB) transfer line. During transfer into the Booster, another 20 electrons are removed from the ions, resulting in a charge state of +32 . Upon injection into the AGS via the Booster-to-AGS (BtA) transfer line, the charge state reaches +77 due to removal of another 45 electrons. Finally, the remaining 2 electrons are removed in the AGSto-RHIC (AtR.) line, leading to fully stripped gold ions to be injected into RHIC. Figure 1 shows the various charge states for gold ions in the BNL accelerator complex.

To preserve small emittances, it is essential to chose the properties of the stripping foils such that emittance degradation during the stripping process is minimized, while at the same time sufficient stripping efficiency is provided. During the FY 2003 RHIC run, systematic studies of the effect of differentstrippingfoils on longitudinalbeam emittance in the BtA line were performed.

While the effect of different stripping foils can be qualitatively seen by comparing longitudinal beam profiles as taken by a wall current monitor, a quantitative analysis requires information on the longitudinal phase space distribution. This is especially true if the bunch under study is not matched to the longitudinal bucket, for then the wall currunt monitor display data vary from turn to tum. For the FY 2003 RHIC run, six gold bunches were accelerated during each Booster cycle and transferred as a bunchtrain into the AGS. Because of the energy loss and associated velocity loss in the BtA stripping foil, at least five of these six bunches are inherently mismatched into the AGS buck-

\footnotetext{
${ }^{*}$ Work performed under the auspices of the U.S. Departmentof Energy
}

\begin{tabular}{lcc}
\hline & carbon & silica \\
\hline thickness [pm] & 125 & 100 \\
non-uniformity[percent FWHM] & 8.30 & 0.50 \\
energy loss [MeV/amu] & 4.7 & 4.0 \\
$\Delta E_{\text {non-uniform }}[\mathrm{MeV}]$ & 32.7 & 1.7 \\
$\Delta E_{\text {Booster }}[\mathrm{MeV}]$ & 10.3 & 10.3 \\
$\Delta E_{\text {stragg }}[\mathrm{MeV}]$ & 2.0 & 3.2 \\
\hline$\triangle E_{\text {AGS }}[\mathrm{MeV}]$ & 34.4 & 10.9 \\
\hline
\end{tabular}

Table 1: Parameters of the two stripping foils.

ets. A tomographic phase space reconstruction technique has therefore been applied to reconstruct the longitudinal phase space distribution of individual bunches, which can then be used to calculate the longitudinal emittance.

\section{STRIPPING FOILS}

Two stripping foils were compared in the BtA line, a $125 \mu \mathrm{m}$ thick carbon foil and a $100 \mu \mathrm{m}$ thick silica foil. Given the foil material and thickness as well as the nonuniformity of the thickness, the expected energy spread in the AGS can be estimated as

$$
\Delta E_{\mathrm{AGS}}=\sqrt{\Delta E_{\text {Booster }}^{2}+\Delta E_{\mathrm{non}-\text { uniform }}^{2}+\Delta E_{\mathrm{stragg}}^{2}}
$$

where $\Delta E_{\text {Booster }}$ is the rms energy spread at Booster extraction, $\Delta E_{\text {non-uniform }}$ is the rms energy spread due to foil non-uniformity, and $\Delta E_{\text {stragg }}$ denotes the rms energy spread caused by straggling. Table 1 lists these parameters for the two foils, together with the resulting expected rms energy spread in the AGS. The resulting energy spread at AGS injection is expected to be about three times smaller for the silica stripping foil than for the carbon foil.

\section{RESULTS}

To determine the longitudinal emittance, longitudinal turn-by-turn beam profiles were recorded with the AGS wall currentmonitor. The digital oscilloscopeused for data acquisition was not synchronizedto the Booster revolution frequency, resulting in an over-estimate of the longitudinal emittanceif not treated in the following way.

After some pre-processing to remove the DC offset, the longitudinal phase space distributionwas reconstructed using an iterative tomographic back-projection technique $[1,2]$. To avoid, systematic errors due to uncertainties in 


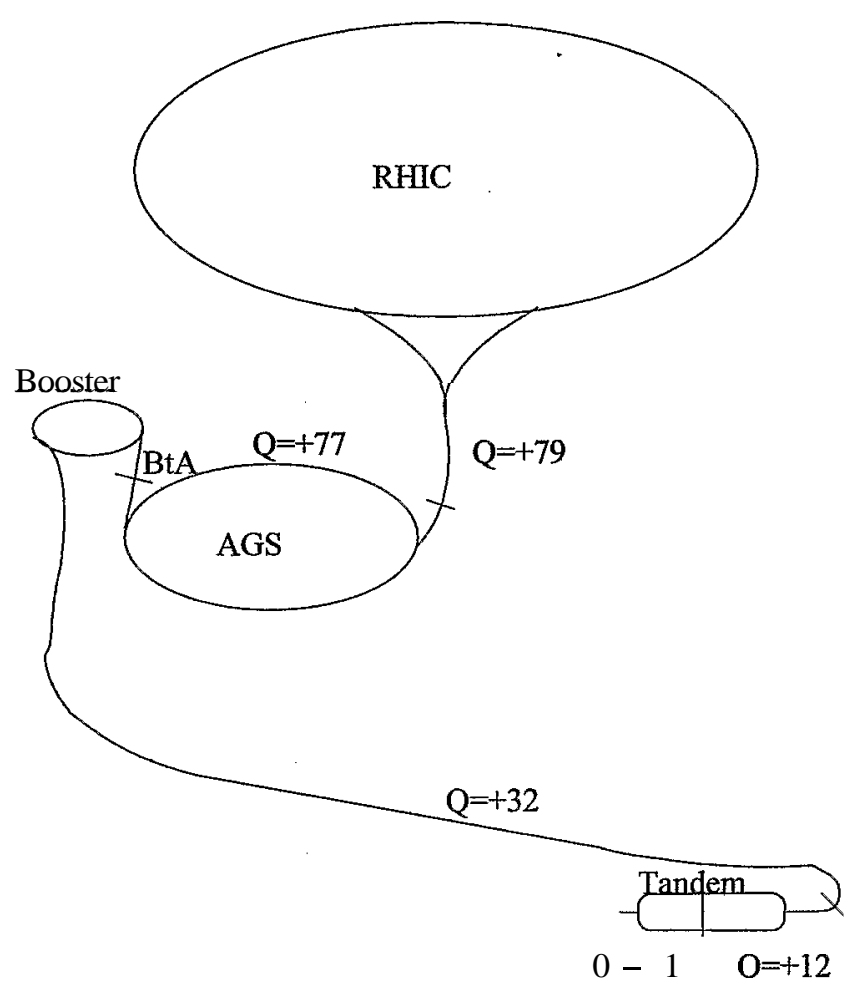

Figure 1: Charge states of gold ions in the BNL accelerator complex.

the RF voltage, a multi-parameter fitting routine was applied to effectively measure this parameter, and to determine the position of the synchronousphase with respect to the injected bunch [2]. Once the correct values for these parameters were found, the resulting emittance of the corresponding phase space distribution was calculated. Since the reconstructionalgorithmtends to produce low-intensity tails in the phase space distribution due to residual noise in the data, all data points below a certain noise level were set to zero during this emittance calculation. This method provides a more accurate emittance value than subtracting the maximum value of that noise level from all data points. This low-intensity noise appears only in relatively few phase space areas, so this process is justified.

As Figure 2 indicates, the resulting longitudinal bunch emittance for the silica foil is significantly smaller than for the carbon foil. Taking the average over 11 bunches for the silica foil, the calculated emittance is $0.46 \mathrm{f} 0.04 \mathrm{eV} \cdot \mathrm{sec}$, comparedtoanaverage of $1.04 \mathrm{f} 0.18 \mathrm{eV} \cdot \mathrm{sec}$ for the carbon foil, computed from 16 bunches.

\section{CONCLUSION}

A tomographicphase space reconstructiontechniquehas been applied to analyze longitudinalemittance growth during the stripping of gold ions in the Booster-to-AGStransfer line of the Brookhaven accelerator complex. With the silica foil, the emittance of the emerging beam is a fac- tor 2.5 smaller than with the carbon foil, which is in good agreement with expectations, as listed in Table 1. This significant improvement results in better re-bucketing performance in RHIC, leading to a higher luminosity. However, the stripping efficiency produced by the carbon foil is greater than that of the silica foil for the desired resulting charge state of $\mathrm{Au}^{77+}$. Beryllium foils are currently under considerationinstead of silica, since beryllium is expected to provide small energy spread together with high stripping efficiency.

\section{REFERENCES}

[1] S. Hancock, M. Lindroos, and S. Koscielniak, "Iongitudinal phase space tomography with space charge", Phys. Rev. ST Accel. Beams 3,124202 (2000)

[2] C. Montag, N. D'Imperio, J. Kewisch, and R. Lee, "Tomographic phase space reconstruction during rebucketing in the Relativistic Heavy Ion Collider", Phys. Rev. ST Accel. Beams 5,082801 (2002) 

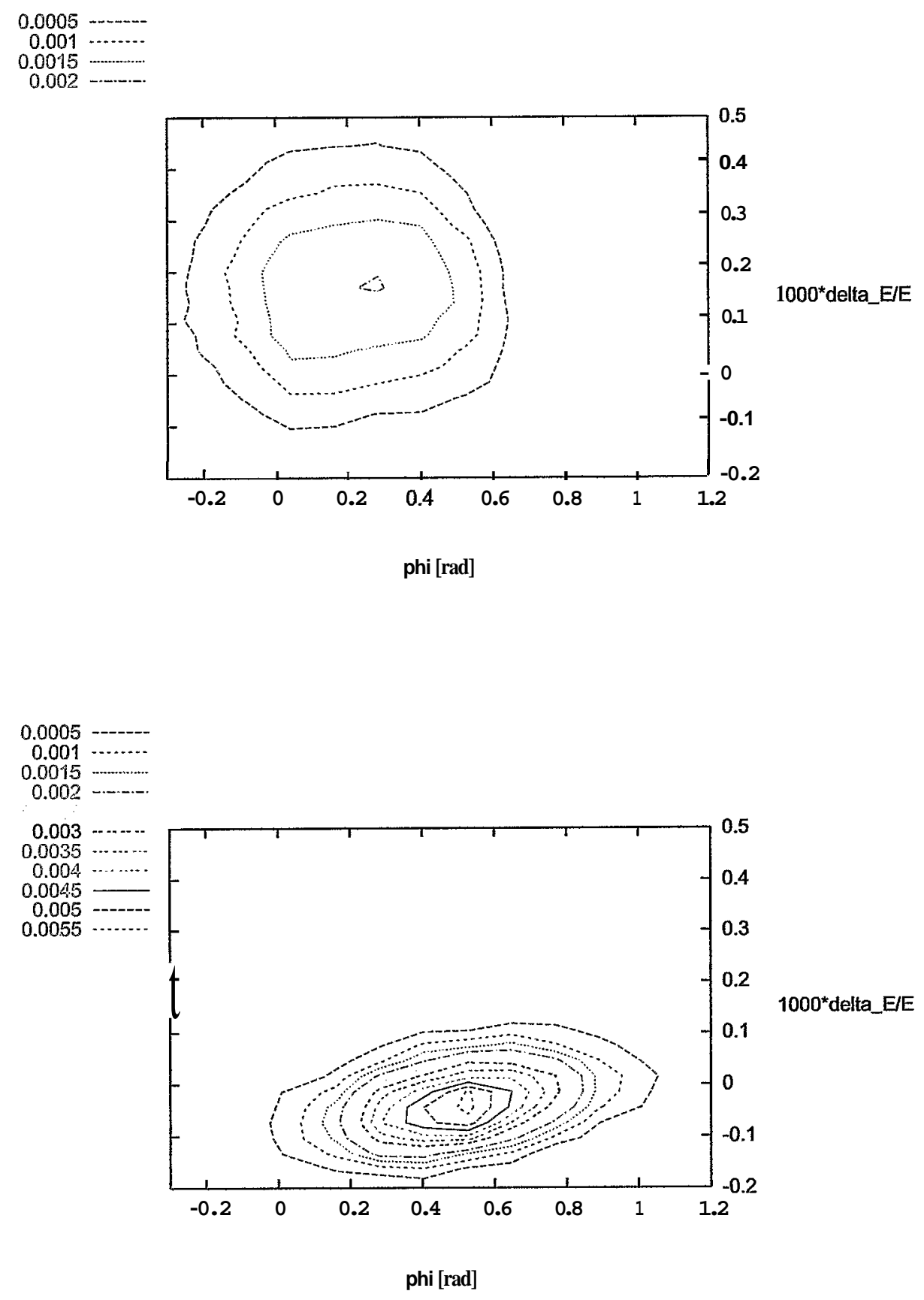

Figure 2: Reconstructed longitudinal phase space at AGS injection, using the carbon foil (top) and the silica stripping foil (bottom). 